\title{
Protocol
}

\section{DNA Immunoprecipitation (DIP) for the Determination of DNA- Binding Specificity}

\author{
Andrea J. Gossett and Jason D. Lieb ${ }^{1}$ \\ Department of Biology, University of North Carolina at Chapel Hill, Chapel Hill, NC 27599, USA
}

\section{INTRODUCTION}

Knowledge of the DNA-binding specificity of a transcription factor aids in understanding the function of that factor in the regulation of gene transcription. One popular method of identifying the genomic DNA sites bound by a given protein in vivo is the Chromatin ImmunoPrecipitation with microarray analysis (ChIP-chip) technique. However, this method reveals a binding pattern influenced by in vivo phenomena that may mask the actual DNA-binding specificity of the factor, such as chromatin effects and competitive or cooperative protein-protein interactions. ChIP-chip also requires adequate expression of the protein in the cell type chosen to create the extract used for immunoprecipitation. DNA Immunoprecipitation (DIP) is an alternative technique that allows one to take advantage of the favorable properties of both in vivo and traditional in vitro techniques (e.g., electromobility shift assay [EMSA] and binding site selection [SELEX]). DIP utilizes naked genomic DNA as a binding substrate for one or more purified recombinant proteins. Because genomic DNA is used as a template in DIP reactions, the results are directly comparable to ChIP-chip or ChIP-seq data. DIP can be carried out in the presence of cofactors such as heterodimer partners, competitors, or small molecule binding inhibitors. After DNA is isolated by DIP, it is most efficiently detected using a highly parallel genomic technique such as a DNA microarray (DIP-chip) or high-throughput sequencing (DIP-seq). In this protocol, we describe a DIP of a yeast (Saccharomyces cerevisiae) protein with yeast genomic DNA.

\section{RELATED INFORMATION}

For more information about the DIP-chip technique, see Liu et al. $(2005,2006)$.

\section{MATERIALS}

CAUTIONS AND RECIPES: Please see Appendices for appropriate handling of materials marked with $<!>$, and recipes for reagents marked with $<R>$.

\section{Reagents}

Amylose resin (3 mg/mL maltose-binding protein [MBP]-binding capacity; New England Biolabs) $<$ R $>$ DIP binding/wash buffer

$<$ R $>$ DIP elution buffer

DNA (genomic, purified and sheared to an average size of $\sim 600 \mathrm{bp}$ )

Genomic yeast DNA from the strain $\mathrm{S} 288 \mathrm{C}$ was purified by $\mathrm{CsCl}$ gradient and sheared by sonication. 
The protein and genomic DNA used for DIP need not be from the same species, and genomic DNA from any species with a sequenced genome can be used.

Protein of interest (MBP-tagged, purified)

Reagents for detection (i.e., a DNA microarray corresponding to the genomic DNA used, or reagents for high-throughput sequencing; see Step 11)

\section{Equipment}

DNA purification columns (e.g., Zymo-Spin I; Zymo Research)

Equipment for detection (i.e., DNA microarray or high-throughput sequencing capacity; see Step 11)

Ice

Microcentrifuge (capable of $2000 \mathrm{~g}$ for microcentrifuge tubes)

Microcentrifuge tubes $(1.5 \mathrm{~mL})$

Rotator (Labquake e.g., Barnstead International 400110 or comparable end-over-end rotator) or micropipettor (see Step 4)

\section{METHOD}

This protocol was modified from the method by Liu et al. (2005).

1. To prepare a $100 \mu \mathrm{L}$ reaction, combine the purified protein of interest (MBP-tagged) to a final concentration of $40 \mathrm{nM}$ and the sheared genomic DNA to a final concentration of $0.3 \mathrm{pM}$ in $100 \mu \mathrm{L}$ DIP binding/wash buffer.

For yeast DIPs, $0.3 \mathrm{pM}$ genomic DNA is equivalent to $200 \mathrm{ng}$ in a 100- $\mu \mathrm{L}$ reaction. The suggested protein concentration of $40 \mathrm{nM}$ is based on a typical DNA-binding protein $K_{d^{\prime}}$ and may be varied according to the protein used.

2. Incubate for $30 \mathrm{~min}$ at room temperature $\left(\sim 22^{\circ} \mathrm{C}\right)$.

3. Wash $10 \mu \mathrm{L}$ of amylose resin with $100 \mu \mathrm{L}$ DIP binding/wash buffer in a $1.5-\mathrm{mL}$ microcentrifuge tube. Centrifuge at $2000 \mathrm{~g}$ for $5 \mathrm{~min}$ in a microcentrifuge at room temperature. Store on ice until Step 4 .

4. Add the protein/DNA reaction mixture $(100 \mu \mathrm{L})$ to the washed amylose resin. Rotate end-over-end on a Labquake rotator for $15 \mathrm{~min}$ at room temperature.

It is essential that the resin remains in suspension during this step. Nutation is insufficient to maintain suspension. If end-over-end rotation is unavailable, frequent (every 30-60 sec) pipetting may be substituted.

5. Centrifuge the resin at $2000 \mathrm{~g}$ for $5 \mathrm{~min}$.

6. Wash the resin with $50 \mu \mathrm{L}$ DIP binding/wash buffer and centrifuge at $2000 \mathrm{~g}$ for $5 \mathrm{~min}$.

7. Repeat Step 6 three additional times for a total of four washes. Remove the supernatant after the final wash.

8. Elute the protein by adding $50 \mu \mathrm{L}$ DIP elution buffer to the resin.

9. Centrifuge the resin at $2000 \mathrm{~g}$ for $5 \mathrm{~min}$ and collect the supernatant.

10. Isolate the DNA from the supernatant with a Zymo-Spin I column (or equivalent DNA purification method) and elute into the desired volume.

A starting amount of $200 \mathrm{ng}$ of yeast DNA (Step 1) typically results in a total yield of 16-30 ng of isolated DNA. The elution volume may be adjusted to achieve the desired final concentration.

11. Amplify and detect the isolated DNA.

$D N A$ isolated by DIP has been successfully amplified by random priming, ligation-mediated $P C R$, and Whole Genome Amplification (WGA) (Genomeplex WGA2; Sigma-Aldrich). Detection options include DNA microarray (DIP-chip) or high-throughput sequencing (DIP-seq) methods. Follow the sample preparation recommendations for the preferred detection technique; detailed methods for the different detection platforms vary by manufacturer and are typically well-described. 


\title{
TROUBLESHOOTING
}

\author{
Problem: Protein recovery fails. \\ [Step 8] \\ Solution: Confirm that the resin remains suspended in Step 4. If the resin is not suspended, the pro- \\ tein will not bind efficiently.
}

Problem: Little to no enrichment of DNA is achieved.

[Step 11]

Solution: Consider the following:

- Determine the optimal number of washes for the protein of interest. The wash conditions were established using MBP-Leu3DBD, but may vary based on the $K_{d}$ of the protein used. Cross-linking the protein and DNA complex with formaldehyde or a similar reversible cross-linker may enhance isolation of DNA when proteins with a low-affinity for DNA are used, but this has not been rigorously tested.

- Confirm that the protein is capable of binding DNA, because some recombinant proteins fail to fold properly. If the consensus sequence is already known, traditional methods (such as EMSA) can be used to check the protein's ability to bind DNA. As an alternative to using recombinant protein, native protein may be purified from the organism of interest. Treatment of the purified protein with DNase prior to DIP-chip will likely be required to remove residual native DNA.

\section{DISCUSSION}

Traditional techniques for studying the in vitro binding specificity of purified proteins, such as EMSA (Garner and Revzin 1981; Ellington and Szostak 1990) and SELEX (Brenowitz et al. 1986; Tuerk and Gold 1990), bypass the difficulties associated with the in vivo ChIP-chip method (see Introduction). However, EMSA typically requires some prior knowledge of binding specificity and cannot assay a wide diversity of DNA sequences simultaneously, while SELEX is subject to over-selection of bound sequences, which may cause significant but lower-affinity interactions to be missed. More recently, several high-throughput techniques have been developed; one example is protein binding microarray (PBM), in which purified protein is directly incubated with a DNA microarray. Detection of DNA fragments bound in the reaction is achieved by fluorescently labeling the protein. Although the arrays used can be comprised of PCR products or oligonucleotides representing the entire genome, recent studies have focused on using "universal" oligonucleotides designed to represent every possible $k$-mer (Mukherjee et al. 2004; Berger and Bulyk 2006; Bulyk 2007).

Both PBMs and DIP-chip can be used to determine in vitro consensus sequences for proteins by assaying millions of artificial or natural DNA sequences in parallel. DIP-chip has been shown to perform as well as traditional assays (SELEX and EMSA) and the ChIP-chip method in identifying consensus sequences (Liu et al. 2005). During DIP, the protein and DNA are in solution during the binding reaction, allowing the protein to sample the DNA in three dimensions and eliminating any physical hindrance caused by having the DNA tethered to a surface. DIP also allows controlled manipulation of the binding conditions, enabling quantitative conclusions to be made about the effect of reaction parameters on DNA-binding specificity. DIP-chip results are directly comparable to ChIP-chip results, because the same genomic DNA template is used for binding. By adding protein cofactors to DIP reactions and then comparing the loci bound in vitro and in vivo, it may be possible to quantify the relative contributions of various factors, such as chromatin structure (Liu et al. 2006) and cofactor-assisted targeting.

\section{REFERENCES}

Berger, M. and Bulyk, M.L. 2006. Protein binding microarrays (PBMs) for rapid, high-throughput characterization of the sequence specificities of DNA binding proteins. Methods Mol. Biol. 338: 245-260.

Brenowitz, M., Senear, D.F., Shea, M.A., and Ackers, G.K. 1986. Quantitative DNase footprint titration: A method for studying protein-DNA interactions. Methods Enzymol. 130: 132-181.

Bulyk, M.L. 2007. Protein binding microarrays for the characteriza- tion of DNA-protein interactions. Adv. Biochem. Eng. Biotechnol. 104: $65-85$

Ellington, A.D. and Szostak, J.W. 1990. In vitro selection of RNA molecules that bind specific ligands. Nature 346: 818-822.

Garner, M.M. and Revzin, A. 1981. A gel electrophoresis method for quantifying the binding of proteins to specific DNA regions: Application to components of the Escherichia coli lactose operon regulatory system. Nucleic. Acids Res. 9: 3047-3060. 
Liu, X., Noll, D.M., Lieb, J.D., and Clarke, N.D. 2005. DIP-chip: Rapid and accurate determination of DNA-binding specificity. Genome Res. 15: 421-427.

Liu, X., Lee, C.K., Granek, J.A., Clarke, N.D., and Lieb, J.D. 2006. Whole-genome comparison of Leu3 binding in vitro and in vivo reveals the importance of nucleosome occupancy in target site selection. Genome Res. 16: 1517-1528.
Mukherjee, S., Berger, M.F., Jona, G., Wang, X.S., Muzzey, D., Snyder M., Young, R.A., and Bulyk, M.L. 2004. Rapid analysis of the DNAbinding specificities of transcription factors with DNA microarrays. Nat. Genet. 36: 1331-1339.

Tuerk, C. and Gold, L. 1990. Systematic evolution of ligands by exponential enrichment: RNA ligands to bacteriophage T4 DNA polymerase. Science 249: 505-510. 


\section{DNA Immunoprecipitation (DIP) for the Determination of DNA-Binding Specificity}

Andrea J. Gossett and Jason D. Lieb

Cold Spring Harb Protoc; doi: 10.1101/pdb.prot4972

\begin{tabular}{rc}
\hline $\begin{array}{r}\text { Email Alerting } \\
\text { Service }\end{array}$ & Receive free email alerts when new articles cite this article - click here. \\
\hline $\begin{array}{c}\text { Subject } \\
\text { Categories }\end{array}$ & Browse articles on similar topics from Cold Spring Harbor Protocols. \\
& Antibodies, general (289 articles) \\
& DNA Modification/Epigenetics (42 articles) \\
& DNA Purification (160 articles) \\
& DNA:Protein Interactions (74 articles) \\
& Genomic DNA (135 articles) \\
& Immunoprecipitation (75 articles) \\
& Molecular Biology, general (1293 articles) \\
& Yeast (288 articles) \\
& Yeast Genetics (135 articles) \\
\hline
\end{tabular}

